\title{
STRATEGI PENGEMBANGAN AGRIBISNIS BUAH NAGA DI PERKEBUNAN SABILA FARM YOGYAKARTA
}

\author{
Vanya Almeira Rizkika \\ Program Studi Agribisnis Fakultas Pertanian Universitas Padjadjaran \\ almeiravanya09@gmail.com \\ Hepi Hapsari \\ Departemen Sosial Ekonomi Fakultas Pertanian Universitas Padjadjaran \\ Rani Andriani Budi Kusumo \\ Departemen Sosial Ekonomi Fakultas Pertanian Universitas Padjadjaran \\ Endah Djuwendah \\ Departemen Sosial Ekonomi Fakultas Pertanian Universitas Padjadjaran
}

Masuk : 19-01-2021, revisi : 13-02-2021 diterima untuk diterbitkan : 16-02-2021

\begin{abstract}
Sabila Farm is a plantation that plants various commodities, and dragon fruit is its superior commodity. But its production and productivity are declining. The purpose of this study is to determine its agribusiness performance, identify strengths, weaknesses, opportunities and threats of business and determine agribusiness development strategies that are appropriate to its condition. This research is conducted through qualitative approach with case study method. Data collection techniques or information by means of participatory observation, in-depth interviews and literature studies. Informants that are being interviewed are the owner and staffs of Sabila Farm. All the data obtained from research are analyzed with SWOT and fishbone analysis. The result of this research is that Sabila Farm has managed its farming business quite well, although there are several obstacles that have caused the lower production and productivity, such as climate condition, lack of labour especially due to Covid19 pandemic, and its traditional technology. Therefore, Sabila has to increase its labour and develop its technology.
\end{abstract}

Abstrak: Sabila Farm adalah perkebunan yang mengusahakan berbagai komoditas, dimana buah Naga adalah komoditas unggulnya. Akan tetapi, produksi dan produktivitasnya semakin menurun. Tujuan dari penelitian ini untuk mengetahui keragaan agribisnis di Sabila Farm Yogyakarta, mengidentifikasi kekuatan, kelemahan, peluang dan ancaman usaha dan menentukan strategi pengembangan agribisnis yang sesuai dengan keadaan. Penelitian ini bersifat kualitatif dengan metode studi kasus, karena seluruh subsistem agribisnis akan diteliti secara mendalam. Teknik pengumpulan data atau informasi secara observasi partisipatif, wawancara mendalam dan studi literatur. Informan dalam wawancara yang dilakukan yaitu owner dan pegawai Sabila Farm. Seluruh data hasil penelitian dianalisis dengan SWOT dan analisis fishbone. Hasil dari penelitian ini yaitu Sabila Farm sudah mengelola usaha taninya dengan cukup baik, walaupun ada beberapa kendala yang menyebabkan semakin rendahnya produksi dan produktivitas, seperti kondisi iklim, kurangnya tenaga kerja karena kondisi pandemi, dan masih sederhananya teknologi. Karena itu, Sabila sebaiknya menambah SDM dan mengembangkan teknologi budidayanya.

Keywords: Strategy, Agribusiness, Dragon Fruit 


\section{PENDAHULUAN}

Sabila Farm merupakan agrowisata yang cukup besar di DI Yogyakarta. Di sana diusahakan berbagai komoditas dengan buah Naga sebagai komoditas unggulan. Selain itu ada juga sirsak, jeruk lemon, srikaya jumbo, pepaya, jambu kristal, dan alpukat. Perkebunan ini memiliki lahan yang cukup luas, dan sebagian dari luas tersebut digunakan untuk budidaya buah Naga. Sabila Farm telah berkembang menjadi perusahaan agrowisata dengan jumlah pengunjung yang tinggi, yaitu sekitar 5000-6000 orang per tahun (Sabila Farm, 2020). Meskipun begitu, produksi dan produktivitas buah Naga di Sabila semakin rendah, sedangkan permintaan pasar tinggi, yaitu 16 ton (Joko Adiyanto, 2011). Hal ini disebabkan akibat keadaan lahan padas yang diduga berdampak pada budidaya buah Naga dan adanya dampak erupsi gunung berapi pada lahan yang digunakan Sabila Farm untuk menanam buah-buahan khususnya buah Naga pun akhirnya kurang sesuai untuk kegiatan usaha tani, karena abu vulkanik yang terkandung dalam lahar dapat menurunkan kadar unsur hara dalam tanah dan menyebabkan pengerasan, perubahan porositas juga permeabilitas tanah. Selain itu, semakin rendahnya produksi dan produktivitas juga dapat disebabkan karena curah hujan yang terlalu tinggi untuk budidaya buah Naga yang masih satu famili dengan kaktus (Rahayu et al, 2014). Karena hal tersebut, maka penelitian mengenai strategi pengembangan agribisnis di Sabila Farm diperlukan. Adapun jumlah produksi dan produktivitas dapat dilihat dari data di tabel 1.

\section{Tabel 1}

Luas lahan, Produksi, dan Produktivitas Buah Naga di Sabila

\begin{tabular}{lccccccc}
\hline \multirow{2}{*}{ No } & \multirow{2}{*}{ Tahun } & \multicolumn{2}{c}{ Luas lahan(ha) } & \multicolumn{3}{c}{ Produksi(kg) } & \multicolumn{2}{c}{ Produktivitas per pohon } \\
& & Merah & Putih & Merah & Putih & Merah & Putih \\
\hline 1 & 2015 & 1 & 1 & $9.757,85$ & $5.938,03$ & 3,253 & 1,484 \\
\hline 2 & 2016 & 1 & 1 & $11.387,65$ & 5.627 & 3,796 & 1,407 \\
\hline 3 & 2017 & 1 & 1 & $4.641,9$ & 674,5 & 1,547 & 0,225 \\
\hline 4 & 2018 & 1 & 1 & $3.671,22$ & $2.362,6$ & 1,224 & 0,591 \\
\hline 5 & 2019 & 1 & 1 & $1.837,22$ & $1.335,4$ & 0,612 & 0,334 \\
\hline 6 & 2020 (sampai dengan bulan Mei) & 1 & 1 & 208,4 & $2.113,16$ & 0,069 & 0,528 \\
\hline
\end{tabular}

Sumber: Sabila Farm (2020)

\section{Tujuan Penelitian}

1. Mengetahui keragaan agribisnis di Sabila Farm Yogyakarta.

2. Mengidentifikasi kekuatan, kelemahan, peluang dan ancaman usaha di Sabila Farm Yogyakarta.

3. Menentukan strategi pengembangan agribisnis yang sesuai dengan keadaan di Sabila Farm Yogyakarta.

\section{TELAAH KEPUSTAKAAN}

Buah Naga (Hylocereus sp.) berasal dari Amerika Tengah, Amerika Selatan dan Meksiko, dan tanaman ini termasuk salah satu tanaman yang sejenis kaktus. Buah Naga termasuk tanaman epifit (akar bertumbuh ke permukaan), tanaman gravitasi dan tanaman berhari panjang. Buah Naga dapat tumbuh optimal di ketinggian 0-350 mdpl, dengan curah hujan $720 \mathrm{~mm} /$ tahun, di tanah pasir atau lempung liat dengan pH 6 (Kristanto, 2009 dalam Renasari,2010). Buah Naga termasuk tanaman yang potensial untuk diusahakan, maka dari itu agribisnis buah Naga perlu dikembangkan. Berdasarkan pernyataan Saragih (1998: 86) agribisnis adalah kegiatan yang berhubungan dengan penanganan komoditi pertanian dalam arti luas, yang meliputi salah satu atau keseluruhan dari mata rantai produksi, pengolahan masukan dan keluaran produksi (agroindustri), pemasaran masukan-keluaran pertanian dan kelembagaan penunjang kegiatan. Strategi pengembangan agribisnis di suatu perusahaan/badan usaha dapat dilihat dengan dua metode, yaitu SWOT dan fishbone. SWOT bertujuan menganalisis kekuatan dan kelemahan suatu perusahaan/badan usaha, serta peluang dan ancaman yang ada dalam kegiatan perusahaan, sedangkan fishbone bertujuan untuk mengetahui masalah yang sebenarnya terjadi di lapangan. 


\section{METODOLOGI PENELITIAN}

Penelitian ini bersifat kualitatif dengan metode studi kasus, Informan yang diwawancarai yaitu owner dan pegawai di Sabila Farm, dan ditentukan secara purposive. Cara mengambil data yaitu dengan wawancara mendalam, pengamatan berpartisipasi, studi dokumen. Setelah itu data dianalisis dengan SWOT dan diagram tulang ikan/fishbone.

\section{HASIL PENELITIAN DAN PEMBAHASAN Keragaan Agribisnis Buah Naga}

Alat yang diperlukan untuk proses budidaya seperti cangkul, garu, dan lain-lain diperoleh dari toko-toko di daerah sekitar. Sabila Farm akan melakukan pembelian secara langsung atau diantar jika lokasi toko cukup jauh dari kebun. Proses budidaya buah Naga di Sabila Farm meliputi persiapan bibit (dengan stek) dan media tanam (mencampurkan tanah dengan pupuk), penanaman dan pemeliharaan, serta panen dan pasca panen. Pemeliharaan yang dilakukan adalah dengan penyiangan, penyulaman, pemupukan, pengikatan, penyiraman, pemangkasan, dan pengendalian HPT. Setelah dipanen, pada dasarnya produk pertanian perlu ditangani terlebih dahulu sebelum dipasarkan. Proses penanganan yang dijalankan yaitu dengan sortasi, pembersihan dan pelabelan. Buah yang sudah dikemas dengan dus dan net foam siap dikirimkan ke mitra-mitra usaha baik di Yogyakarta maupun di luar Yogyakarta. Sedangkan untuk penjualan langsung di lokasi kebun, buah Naga akan dijual langsung secara eceran. Sabila Farm sudah memiliki izin usaha berbentuk UD (Usaha Dagang). Dari segi pendidikan dan pelatihan. Sabila Farm memberi pelatihan pada karyawannya. Dari segi modal, Sabila membiayai seluruh kegiatan usahanya dengan modal sendiri.

\section{Analisis Masalah dengan Metode SWOT}

Pengembangan agribisnis dapat dianalisis dengan SWOT. Analisis SWOT pada Sabila Farm adalah sebagaimana ditunjukkan pada tabel 2.

\section{Tabel 2}

\section{Identifikasi SWOT}

\begin{tabular}{|c|c|c|}
\hline Eksternal & $\begin{array}{l}\text { Kekuatan (Strength) } \\
\text { 1. Modal mencukupi untuk budidaya } \\
\text { 2. Adanya pelatihan } \\
\text { 3. Pemasaran luas dan terintegrasi } \\
\text { 4. Produk berkualitas }\end{array}$ & $\begin{array}{l}\text { Kelemahan (Weaknesses) } \\
\text { 1. Jumlah SDM kurang mencukupi sehingga } \\
\text { terjadi rangkap jabatan } \\
\text { 2. Kurang memanfaatkan teknologi dalam } \\
\text { budidaya dan sistem online dalam pemasaran } \\
\text { dan promosi } \\
\text { 3. Kurangnya kerja sama dengan saluran } \\
\text { distribusi lain } \\
\text { 4. Harga produk mahal dan masih dibutuhkan } \\
\text { stimulus produksi }\end{array}$ \\
\hline Peluang (Opportunities) & Strategi $(\mathbf{S}+\mathbf{O})$ & Strategi $(\mathrm{W}+\mathrm{O})$ \\
\hline $\begin{array}{l}\text { 1. Pesaing berpotensi dijadikan } \\
\text { mitra } \\
\text { 2. Budaya hidup sehat yang } \\
\text { mulai diterapkan } \\
\text { 3. Jumlah penduduk cukup } \\
\text { banyak }\end{array}$ & $\begin{array}{l}\text { 1. Peningkatan mitra dengan } \\
\text { perusahaan lain (pesaing dan selain } \\
\text { pesaing) } \\
\text { 2. Jalin kerjasama dengan penduduk } \\
\text { (misalkan sebagai marketer dan } \\
\text { reseller) }\end{array}$ & $\begin{array}{l}\text { 1. Jadikan pesaing sekaligus mitra pemasaran } \\
\text { dan promosi } \\
\text { 2. Peningkatan kerja sama dengan saluran } \\
\text { distribusi lain misalkan travel } \\
\text { 3. Memaksimalkan teknologi budidaya, juga } \\
\text { teknologi adaptasi musim } \\
\text { 4. Menambah SDM dan meminjam modal ke } \\
\text { pihak investor/bank untuk menstimulasi } \\
\text { produksi }\end{array}$ \\
\hline Ancaman (Threat) & Strategi $(\mathbf{S}+\mathbf{T})$ & Strategi $(\mathrm{W}+\mathrm{T})$ \\
\hline $\begin{array}{l}\text { 1. Adanya persaingan dengan } \\
\text { bentuk usaha lain } \\
\text { 2. Jumlah tenaga kerja potensial } \\
\text { yang tersedia di luar sedikit } \\
\text { 3. Curah hujan tinggi }\end{array}$ & $\begin{array}{l}\text { 1. Inovasi produk dan layanan } \\
\text { 2. Pengadaan pelatihan kepada } \\
\text { masyarakat sekitar }\end{array}$ & $\begin{array}{l}\text { 1.Pembagian SDM di Sabila diperhatikan lagi } \\
\text { 2. Peningkatan penggunaan media online dalam } \\
\text { pemasaran dan promosi } \\
\text { 3. Peninjauan kembali dalam penetapan harga }\end{array}$ \\
\hline
\end{tabular}

Dari segi SDM, jumlahnya kurang mencukupi sehingga dapat menghambat jalannya usaha secara keseluruhan. Terlebih lagi tenaga kerja berpengaruh signifikan terhadap produksi pertanian (Usman,2018). Maka dari itu Sabila perlu memperhatikan kuantitas SDM yang dimiliki, terutama pada pekerja kebunnya. Tidak hanya kuantias, pengetahuan dan 
keterampilan yang memadai diperlukan oleh pekerja kebun karena kurangnya pengetahuan dan keterampilan pekerja dapat menyebabkan kesalahan dalam cara budidaya (Ramadhan, 2015). Selain itu, dengan kualitas petani yang baik akan mampu menunjang keberlanjutan usaha budidaya secara keseluruhan (Adiyanto,2011). Positifnya, kualitas buah Naga Sabila berbuah lebih cepat dan kualitasnya lebih baik, karena varietas unggul buah Naga Sabila yang diciptakan dengan kultur jaringan, sesuai dengan fungsinya untuk menghasilkan bibit unggul (Marina,2014). Apabila ditinjau dari subsistem agroindustri, Sabila Farm sudah menjual banyak produk olahan, namun karena kondisi pandemi saat ini produksi buah Naga makin menurun maka pembuatan produk olahan dihentikan sementara, sehingga terjadi penurunan pendapatan. Hal ini sesuai dengan penelitian Nayaka (2018) yang menyatakan bahwa modal berpengaruh signifikan dalam proses pengolahan. Oleh karena itu Sabila perlu mencari cara agar penjualan tetap berjalan dengan baik, misalkan selain menjual buah segar, pembuatan produk olahan juga digalakkan kembali. Mengingat jumlah penduduk Sleman yang cukup banyak yaitu mencapai 1,18 juta jiwa (BPS,2017) maka kemitraan sangat penting untuk dipertahankan dan diperluas. Kemitraan secara umum memiliki banyak peranan, di antaranya mendukung pemasaran agar tetap berjalan baik, yang akan berpengaruh positif pada pendapatan usaha (Syaifun,2015). Oleh karena itu pemasaran perlu untuk dipertahankan dan diperluas lagi, misalkan dengan melakukan penyesuaian harga sebelum memasukkan produknya ke pasar modern, dikarenakan konsumen pasar biasanya akan memilih produk dengan harga yang terjangkau. Artinya harga mempunyai pengaruh siginfikan terhadap keputusan pembelian (Dido,2005 dalam Andita,2017).

\section{Analisis Masalah dengan Metode Fishbone (Tulang Ikan)}

Kegiatan usaha di Sabila Farm dapat dianalisis dari beberapa aspek, di antaranya manusia, metode, lingkungan dan mesin. Lebih jelasnya ditunjukkan di gambar 1.

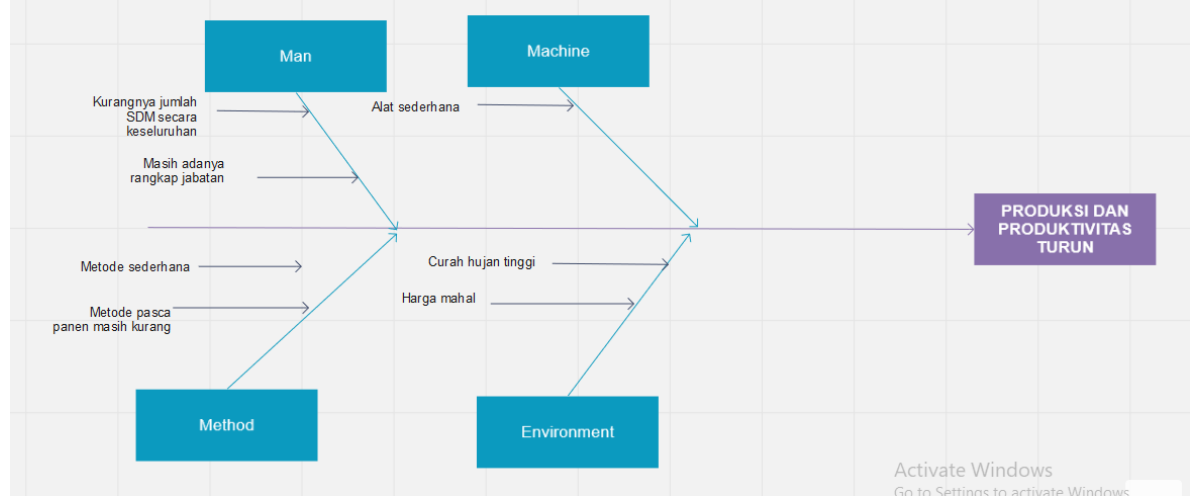

Gambar 1

Hasil Fishbone Analysis

Lahan yang digunakan Sabila Farm merupakan lahan padas yang tidak sesuai untuk kegiatan usaha tani pada umumnya dan memiliki tingkat curah hujan yang terlalu tinggi untuk budidaya buah Naga, dimana curah hujan idealnya adalah $720 \mathrm{~mm} / \mathrm{tahun}$. Kedua hal ini sudah disiasati dengan pembuatan petakan khusus untuk pupuk dan pembuatan parit (Sabila Farm,2020). Akan tetapi lebih baik lagi apabila Sabila menerapkan teknik penciptaan varietas tahan hujan melalui kawin silang, karena pada dasarnya buah Naga tidak tahan terkena air dan genangan dalam waktu lama (Kristanto,2009 dalam Renasari,2010). Selain itu, pengairan menggunakan pipa juga diperlukan agar dapat menghemat biaya (Renasari,2010). Teknologi yang sejauh ini diterapkan di Sabila Farm adalah teknologi pencahayaan lampu yang mengkondisikan penyinaran tanaman lebih dari dua belas jam untuk menstimulus munculnya bunga dan buah di luar musim. Tetapi jarak antar lampu sebaiknya diatur agar lebih dekat, karena dengan itu semua tanaman dapat berbuah dan menghasilkan buah yang lebih banyak. Dari sisi SDM, jumlah pegawai kebun masih kurang sehingga dapat menghambat jalannya usaha secara keseluruhan. Idealnya satu hektar ditangani oleh dua orang pekerja kebun (Sabila Farm,2020). 


\section{Strategi Pengembangan Agribisnis Buah Naga}

Berdasarkan fishbone : penambahan jumlah SDM, penggunaan teknologi budidaya. Berdasarkan SWOT : peningkatan kemitraan, dan penambahan SDM

\section{KESIMPULAN DAN SARAN}

Pada umumnya keragaan agribisnis di Sabila sudah baik, walaupun ada beberapa yang masih harus diperbaiki. Kelebihan Sabila ada pada kualitas produknya, sedangkan kelemahan Sabila ada pada sumber daya manusianya. Sabila memiliki peluang usaha dari kebiasaan penduduk untuk hidup sehat, tetapi kegiatan usahanya dapat terancam karena faktor iklim, di antaranya curah hujan. Alternatif solusi yaitu penambahan SDM, mempertahankan kualitas produk dan memperluas jaringan pemasaran. Selain itu, Sabila sebaiknya mempertahankan kekuatan dari segi kualitas dan memperbaiki kelemahan dari segi SDM. Adapun secara khusus, langkah yang dapat dilakukan yaitu penambahan SDM, penerapan teknologi produksi yang lebih modern, penerapan teknologi adaptasi musim, dan perluasan pemasaran.

\section{DAFTAR PUSTAKA}

Adiyanto, J. (2011). Strategi Pengembangan produksi buah naga merah di Kabupaten Sukoharjo. Skripsi. Sosial Ekonomi Pertanian, Fakultas Pertanian, Universitas Sebelas Maret.

Andita, A. (2017). Pengaruh iklan, harga dan kualitas produk terhadap minat beli ulang konsumen. Skripsi. Jurusan Manajemen, Fakultas Ekonomi, Universitas Sanata Dharma.

Badan Pusat Statistik. (2017). Jumlah Penduduk dan Kepadatan Penduduk menurut Kabupaten/Kota di DI Yogyakarta, 2016.

Marina. (2014). Bahan Ajar Kultur Jaringan. Prodi Pendidikan Biologi, Fakultas Keguruan dan Ilmu Pendidikan. Universitas Kristen Indonesia.

Naim, S., Sasongko, L. A., \& Nurjayanti, E. D. (2015). Pengaruh kemitraan terhadap pendapatan usahatani tebu (Studi kasus di Kecamatan Tayu Kabupaten Pati Provinsi Jawa Tengah). Jurnal MEDIAGRO, 11(1), 47-59. Program Studi Agribisnis, Fakultas Pertanian Universitas Wahid Hasyim.

Nayaka, K. W., \& Kartika, I. N. (2018). Pengaruh modal, tenaga kerja, dan bahan baku terhadap pendapatan pengusaha industri sanggah di Kecamatan Mengwi. E-Jurnal Ekonomi dan Bisnis Universitas Udayana, 7-8, 2018, 1927-1956. Fakultas Ekonomi dan Bisnis, Universitas Udayana.

Ramadhan, M., \& Pomolango, R. (2015). Studi kendala penerapan agribisnis buah naga di desa lubuk lancang Kecamatan Suak Tapeh Kabupaten Banyuasin. Jurnal Societa, IV(1), 1826, Juni 2015. Program Studi Agribisnis, Fakultas Pertanian Universitas Muhammadiyah Palembang.

Rahayu, Ariyanto, D. P., Komariah, Hartati, S., Syamsiyah, J., \& Dewi, W. (2014). Dampak erupsi Gunung Merapi terhadap lahan dan upaya-upaya pemulihannya. Jurnal Ilmu-Ilmu Pertanian, 14(1). Fakultas Pertanian, Universitas Sebelas Maret. Surakarta.

Renasari, N. (2010). Budidaya buah naga Super Red di Wana Bekti Handayani. Tugas Akhir. Diploma 3 Agribisnis Hortikultura, Fakultas Pertanian, Universitas Sebelas Maret Surakarta.

Saragih, B. (1998). Paradigma Baru Pembangunan Ekonomi Berbasis Pertanian (Kumpulan Pemikiran). Bogor: Yayasan Persada Mulia Indonesia.

Usman, U., \& Juliyani (2018). Pengaruh luas lahan, pupuk, dan jumlah terhadap produksi padi Gampong Matang Baloi. Jurnal Ekonomi Pertanian Unimal, 1(1), Mei 2018. Fakultas Ekonomi dan Bisnis. Universitas Malikussaleh. 